\title{
Different applications of concept maps in Higher Education
}

\author{
Amparo Bes Piá, Encarna Blasco-Tamarit, María José Muñoz-Portero \\ Equipo de Innovación y Calidad Educativa sobre Técnicas de Evaluación Continua Formativa - \\ Universidad Politécnica de Valencia (SPAIN) \\ mbespia@iqn.upv.es; meblasco@iqn.upv.es;mjmunoz@iqn.upv.es
}

Received November 2010

Accepted March 2011

\section{Abstract:}

Purpose: The aim of this work is to show different applications of concept maps in higher education, concretely in qualifications of the Polytechnic University of Valencia.

Design/methodology/approach: Different methodologies have been used depending on the application of concept maps: as evaluation tool, as knowledge organizing tool, and as meaningful learning tool.

Findings: Students consider the concept maps useful principally to select key ideas, to achieve a comprehensive view of the lesson, and to bring up the subject. Moreover, concept maps promote the meaningful and active learning, help students to understand, follow-up, and learn subjects with a high load of contents.

Research limitations/implications: The most important limitation is the use of the concept maps in subjects with a high number of students.

Practical implications: The realization of concept maps allows the student to develop generic competences.

Originality/value: The originality of this work is to show how a same tool can be used in different subjects of different qualifications.

Keywords: concept map, evaluation tool, knowledge organizing tool, meaningful learning 


\section{Introduction}

Concept maps were created by D. Novak (Novak \& Gowin, 1988), professor at the University of Cornell, in the 1970s. He developed this tool based on the meaningful learning theories of Ausubel. Novak bet on concept maps as a high efficiency tool to evaluate, organize knowledge, and improve the meaningful learning or teamwork (Novak, 1982). A concept map is a diagram that collects a group of concepts. These concepts are significantly related by means of linking words with the aim of building meaningful sentences denominated propositions. In these diagrams, concepts are usually represented as boxes and their relationships are showed by arrows labeled with the linking words. Figure 1 shows a concept map example.

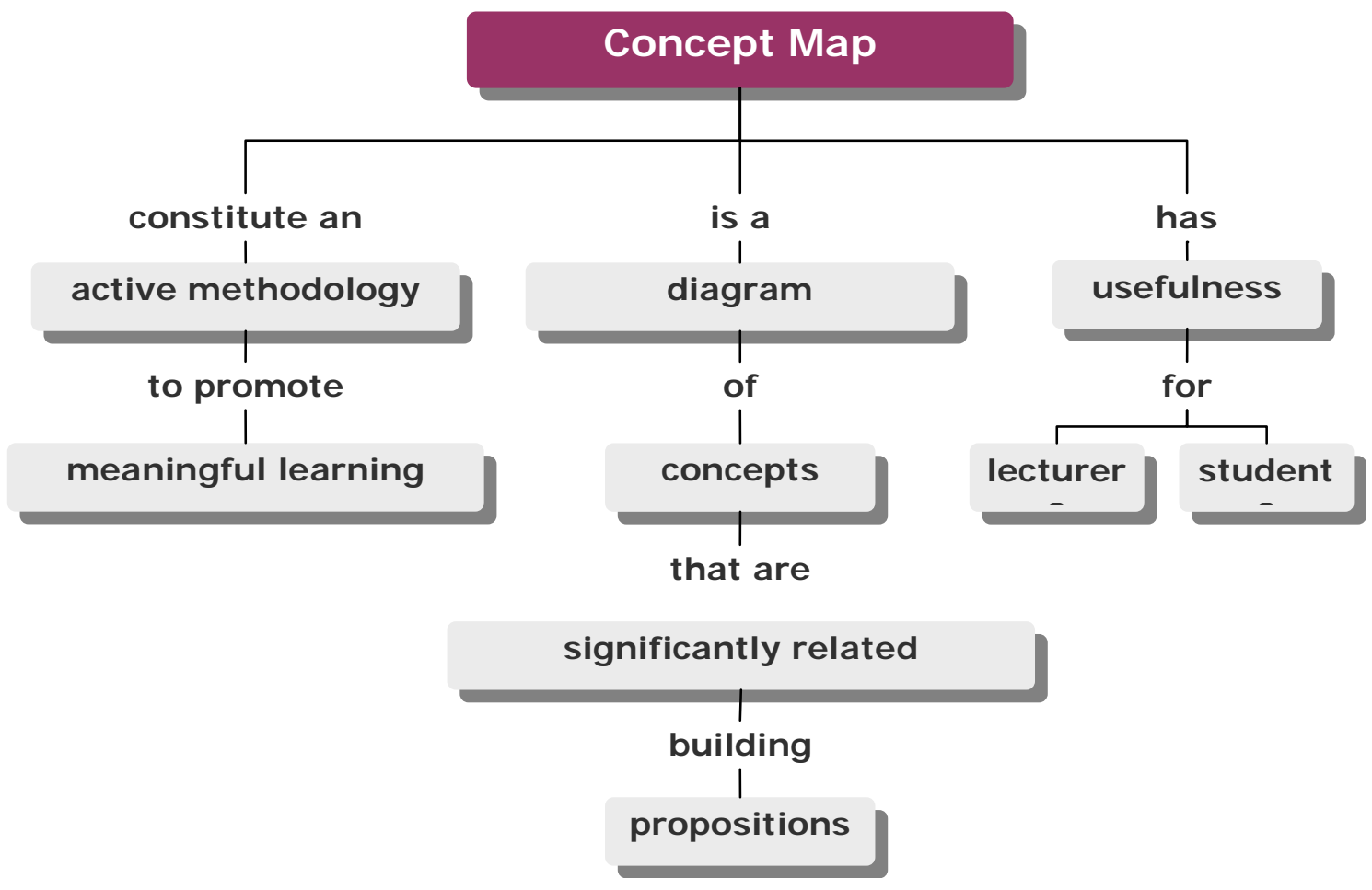

Figure 1. "Concept map about concept maps".

According to Ausubel, the most important factor that has influence on learning is the previous knowledge that we have, since the meaningful learning occurs when relationships are established between new and previous concepts (Ausubel, 1968; Ausubel, 2002). When the meaningful learning takes place, some changes in our 
cognitive structure occur, modifying the previous concepts, and linking them with the new ones. As a consequence, the learning remains during more time and it can be applied easily to solve problems. On the contrary, rote learning focused on memorization, which adds arbitrary concepts to the cognitive structure letting them to forget soon.

The adaptation of the Spanish University to the European Space for Higher Education means the replacement of the present credit system by the European Credit Transfer System (ECTS). The first one is based on number of hours that the student attends to classes, while the ECTS is based on the student total workload necessary to achieve abilities, knowledge, and skills of a subject. ECTS includes the total number of working hours of the student, that is the sum of the hours that the students attend to class and the hours that the student work out of the class (Instituto de Ciencias de la Educación de la UPV, 2006).

As a result, changes in teaching-learning methodologies are required; especially those that get better the active and meaningful learning of the students. In this context, concept maps represent an active methodology since students act as an active agent finding relationships between new and previous concepts in an organized structure (diagram).

This tool can be applied to any discipline (basics, social or applied sciences) and at any level of education (since nursery education until high education). In this way, they can be applied as a technique to study or as a learning tool promoting reflection, analysis, and creativity.

Concept maps imply some advantages for students and lecturers. On the one hand, concept maps allow students to:

- Detect important concepts easily and their relationships.

- Organize the school materials.

- Remind previous knowledge.

- Organize learning into a hierarchy.

- Improve the widening of the knowledge from the previous one. 
- Apply this tool to other learning contents (as a model).

- Explore previous knowledge concerning to a new subject and incorporate new information.

On the other hand, concept maps let lecturers:

- Check student learning.

- Transmit complex ideas.

- Evaluate the understanding.

- Identify the lack of understanding.

- Explore concept mistakes.

- Measure concept understanding (evaluating tool).

To sum up, it can be stated that concept maps improve teaching quality. This idea is reinforced by some authors that had empirically verified it (Novak, 1998; Ontoria Peña, 2004; Heinzefry \& Novak, 1990; Hay, Kinchin, \& Lygo-Baker, 2008; González, I báñez, Casalí, López, \& Novak, 2000).

Regarding to the state of the art of concept maps, some examples of research papers about the current applications of concept maps in different areas are shown below:

- Concept mapping as an assessment tool in higher education activities: Concept mapping can be used as an assessment tool and it can be as flexible as it is needed. Authors propose at least three categories for concept maps used in assessment: maps with open propositions, maps with closed propositions, and maps with semi-open propositions (Alonso \& Araya, 2008).

- Making Learning Visible: The Role of Concept Mapping in Higher Education: This article develops the concept-mapping method as a tool for enhancing teaching quality in higher education. In particular, it describes how concept mapping can be used to transform abstract knowledge and understanding 
into concrete visual representations that are amenable to comparison and measurement (Hay, Kinchin, \& Lygo-Baker, 2008 ).

- Bridging the Gap between Expert-Novice Differences: The Model-Based Feedback Approach: This study investigates different types of automatically generated feedback. Seventy-four students participated in the experimental study, in which they had to write texts and create concept maps reflecting their understanding of climate change while receiving three different forms of model-based feedback (Ifenthaler, 2010).

- Cognitive Ability and the Instructional Efficacy of Collaborative Concept Mapping: Data were gathered from 248 secondary students who learned about the circulatory system in 77 self-selected collaborative groups. The learning outcomes of biology students who summarised by collaborative concept mapping were compared with those of students who summarised by collaborative writing. Learning groups randomly assigned to construct concept maps instead of conventional summaries generated more relations in the summary task and their members obtained higher individual scores on a post-test (Haugwitz, Nesbit, \& Sandmann, 2010).

- An Enhanced Concept Map Approach to Improving Children's Storytelling Ability: Storytelling is an imperative and innovative pathway to enhance learning due to the fact that such activity prompts learners to reflect to construct meaning based on their observations and knowledge. Since storytelling involves complex cognitive processes, this study proposed an enhanced concept map approach featured with story grammars to help children develop stories (Chen-Chung, Holly, Ju-Ling, Guo-Ting, \& BawJhiune, 2011).

In other hand, concept maps are currently used in areas out of the higher education as: Organizational Development \& Strategic Planning, Needs Assessment, Curriculum Development, and Evaluation (http://www. conceptsystems.com/projects). 


\section{Experimental design}

\subsection{Aim of the experiment}

The aim of this work is to explain different applications of concept maps in higher education, concretely in qualifications of the Polytechnic University of Valencia. The concept maps were used as evaluation tool, as knowledge organizing tool, and as meaningful learning tool.

\subsection{Participants' profiles}

The participants of the experiments belongs to different subjects, and so they have different profiles depending on the application of concept maps considered.

\section{Evaluation tool}

The experiment based on the application of concept maps as an evaluation tool has been carried out in a subject denominated "Waste Management Engineering" since the academic year 2008-2009. This subject, from the fifth year of Chemical Engineering degree imparted in the Higher Technical School of Industrial Engineering in the Polytechnic University of Valencia. It is an optative subject that belongs to the environmental speciality. The subject consists of 7 credits. The number of students (7-13) allows an easy introduction of new teaching methodologies. The use of this tool is being promoted by the present education framework referring to new pedagogical approaches to teaching and learning abilities.

\section{Knowledge organizing tool}

The experiment based on the application of concept maps as a knowledge organizing tool has been carried out in a subject denominated "Waste Water Engineering" since the academic year 2008-2009. This subject, of the fourth year of Chemical Engineering degree imparted in the Higher Technical School of Industrial Engineering in the Polytechnic University of Valencia. It is an optative subject that belongs to the environmental speciality. The subject consists of 7 credits. The total number of student varied 10-15 and, in general, students have interest in the subject. 
In this case, the aim of using concept maps as a knowledge organizing tool is to help students in the understanding and follow-up of a subject with a high load of contents. Thus, this tool is applied by the lecturer in the both above mentioned scenarios.

\section{Meaningful learning tool}

a) Concept maps achieved in teamwork and used as meaningful learning tool

The concept maps have been used to favour the meaningful learning and the cooperative work in the subject "Chemical Processes Technology" since the academic year 2006-2007. The participants of this experiment are in an optative subject in the third year of the Business Administration and Management degree in the Faculty of Business Administration and Management of the Polytechnic University of Valencia. The subject consists of 4.5 credits. The number of students is around 15-20.

b) Concept maps achieved individually and used as meaningful learning tool

The experiment based on the application of concept maps as a meaningful learning tool individually has been carried out since the academic year 2007-2008 in the subject "Analytical Techniques of the Environment" in the fifth year of the Chemical Engineering degree imparted in the Higher Technical School of Industrial Engineering in the Polytechnic University of Valencia. This is an optative subject, which belongs to the environmental speciality. The subject consists of 5 credits. The total number of student is around 7-15.

\section{Method followed}

In this work, the application of concept maps is divided into three sections.

\subsection{Evaluation tool}

The aims of this activity are to test the previous knowledge related to the present subject and to review previous concepts studied in other subjects, which understanding is basic to continue learning. The use of concept mapping is justified by Ausubel in defining that the main factor in learning is the previous knowledge 
that we have acquired, what would make it useful to test this knowledge level as start point and arrange further actions coherently (Ausubel, 1968).

Before starting, lecturer explains the aim and the profits of the activity in order to motivate the students and to avoid the feeling of obligation (Alonso, 2001).

After that, it is introduced an explanation of what is a concept map, which are its objectives, and how it is being built. The following steps are defined to construct a concept map (González, 2000):

1. To identify key words in a list.

2. To organize them into a hierarchy (general $\rightarrow$ particular).

3. To transfer the organization to a diagram.

4. To relate concepts by means of arrows labelled with linking words (prepositions).

The development of this activity is being carried out in teams so as to promote the personal relations, and the opinions flow, thus leading to a bigger efficiency and dimension of the analysis work (Ausubel, 2002).

The teacher divides up the groups into 3 members teams looking for enabling the work. The most proper criteria for the building of the teams is trying to look for the complementary aspect of the individual capabilities.

In this case it has not been applied an specific tool for knowing the students' skills since the teacher has given previous classes in other subjects of the Chemical Engineering degree with the same students.

Next, the lecturer raises some questions to the teams that have to be answered by means of concept maps building. Due to the lack of familiarization of the students with this tool, the lecturer can provide, if he so considers, blind diagrams and the key words as adivise or help. However, the diagrams are only a guide and thus they can be modified by the students. During this activity, the lecturer has the role of guide.

Finally, each group must present the concept maps to the whole class group and discuss the different proposals. For each question, the presentation time should roughly not exceed 5 minutes. 
Since the aim of this activity is to evaluate the previous knowledge of a subject, it should not be considered for any evaluation mark.

\subsection{Knowledge organizing tool}

\section{Overview of the subject contents}

The teacher develops a concept map containing the keywords of this matter and their relationships. This concept map also includes concepts previously studied in other environmental subjects and that are required to understand the new ones. In this way an overview of the whole subject is introduced in the first class day to the students instead of merely presenting the traditional index content.

\section{$\underline{\text { Remembering introduction }}$}

The aim of this application is to remember the main concepts of an already studied lesson and to easier acquire their learning. For that, at the beginning of each class, the teacher writes in the blackboard a brief concept map of the lesson, containing the main keywords explained until that moment. Next, the teacher adds the new concepts to be learnt at the present lesson.

As in the previous case, the teacher builds the concept maps. Optionally, the students can use them as a model and enlarger them for studying and better understanding of the subject.

\subsection{Meaningful learning tool}

The concept maps as meaningful learning tool can be used to promote both the cooperative and the autonomous work. Here there are showed two examples of the use of concept maps as meaningful learning tool.

a) Concept maps achieved in teamwork and used as meaningful learning tool

Activity development: the lecturer

- 1 o Stage: Activity presentation

During this stage the lecturer explains the definition of a concept map, its applications, and how to construct it. Useful bibliography is also recommended, as (Novak, 1998; Ontoria Peña, 2004; González et al., 2000; HIMC Cmap Tools). The 
lecturer emphasizes the fact that the use of concept maps is not restricted to this subject, if not it can be used in any subject or in the professional activity (meetings and resources organization...).

The guidelines of the concept maps are also provided to the students: deadlines, percentage in which they contribute to the final mark, issues to be considered... Concretely, students must construct one concept map about each lesson that was gave by the lecturer in the class, and they must deliver it one week after the end of the lesson. This deadline was negotiated with the students. The delivery of the concept maps was voluntary and represents the $5 \%$ of the final mark of the subject.

The concept maps were developed in teamwork to promote the cooperative work and the development of social and communicative abilities.

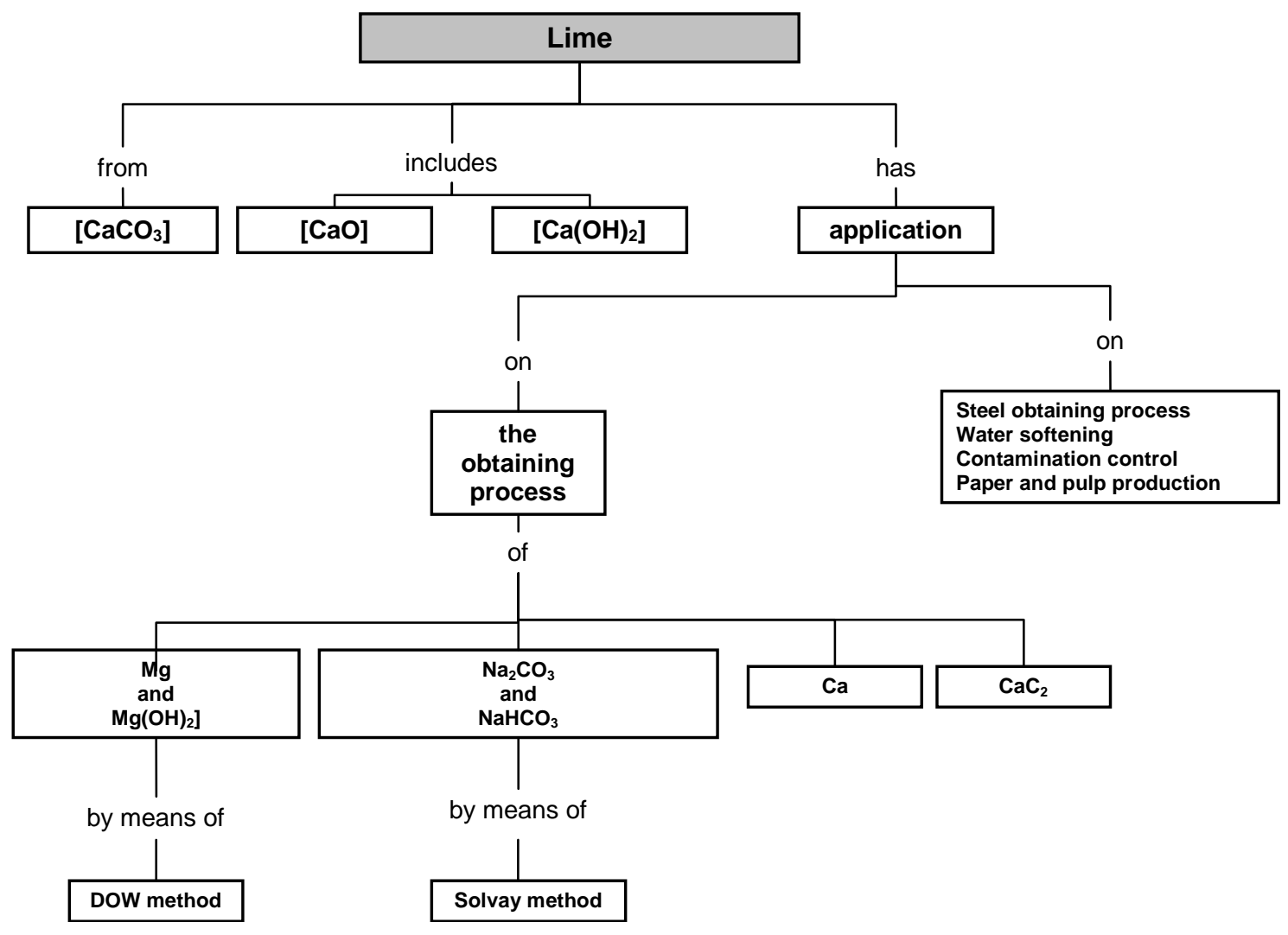

Figure 2. "Example of concept map elaborated by the lecturer in the subject Chemical Processes Technology". 
- 2o Stage: Examples of concept maps

The subject is divided in 12 lessons. The lecturer provides examples of concept maps of the first and second lesson to the students to explain step by step how to construct them. An example of one of this concept map elaborated by the lecturer is shown in Figure 2.

- 3o Stage: Evaluation of the concept maps

The lecturer has also a deadline to deliver the mark of each work. This deadline is one week after the delivery of the concept maps by the students. The lecturer provides the correction criterions to the students. These are:

o Selection of the concepts.

o Hierarchization of the concepts.

o Relationships between concepts.

- 4o Stage: Return of the concept maps (feedback)

The revised and corrected concept maps are returned to the students (so then it is not possible to show an example). They can identify conceptual mistakes, erroneous connections between concepts... The most generalized mistakes are commented in the class.

- 5o Stage: Opinion poll about the usefulness of the concept maps to the students

This opinion poll was use by the lecturer to know the opinion of the students about the usefulness of the concept maps in this subject. Specifically, it was interesting to know if the concept maps allowed a better understanding of the subject or they only were used to increase the final mark.

\section{Activity development: the student}

- $\quad 1$ o Stage: Students must achieve a meaningful reading of each lesson.

- 2o Stage: They must select the most important concepts of each lesson. 
- 3o Stage: They must group the concepts with a close relationship.

- 4 o Stage: They must hierarchies the concepts from the most abstract and general ones to the most concrete and specific ones.

- 5o Stage: They must locate the concepts on the concept map.

- 60 Stage: They must connect and relate the different concepts by means of linking words to build propositions.

- 70 Stage: They must reflect about the propositions formed and, if it is possible, they should contribute with new knowledge about the studied lesson.

- 8o Stage: They must deliver the concept maps to the lecturer one week after the end of the lesson.

- 9o Stage: Feedback based on the lecturer corrections.

b) Concept maps achieved individually and used as meaningful learning tool

One of the methodology applied in the subject is the realization of concept maps individually as an activity of autonomous work. Students receive formation about the concept maps in the first class day: the lecturer explains what a concept map is, what is its usefulness, and how the concept maps are constructed. The lecturer also show examples of concept maps and recommend bibliography.

Students must construct one concept map of each lesson of the subject after it is explained by the lecturer in the class. The students must deliver a total number of concept maps of 10: 5 in the section of water contamination and 5 in the section of atmospheric contamination. The concept maps can be realized manually or using a computer program, as cMap Tools (HIMC Cmap Tools). The deadline for the delivery of the concept maps by the students is one week since the lesson is ended in class. The lecturer has a deadline of one week for the correction and assessment of each concept map. During the delivery of the corrected concept maps, the lecturer has feed-back with the student about the mistakes found. The concept maps represent $20 \%$ of the final score of the subject, and it is a voluntary activity. Figure 3 shows an example of one of the concept maps elaborated by the students. 


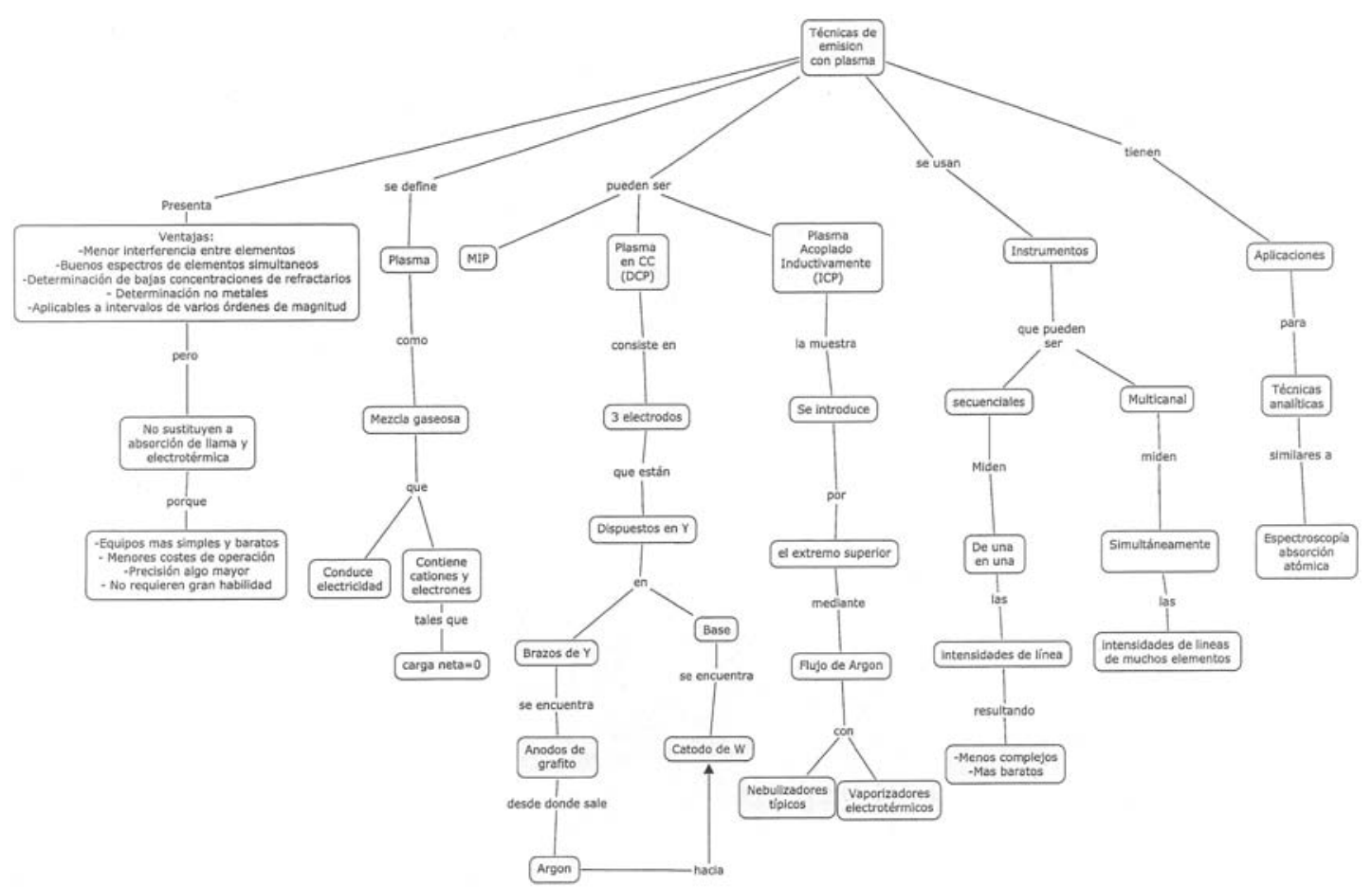

Figure 3. "Example of concept map elaborated by the students in the subject Analytical Techniques of the Environment".

Students fill out an opinion poll of the subject the last class day. The opinion poll has two parts. In the first part, the students must fill out a table with the strong points and the weak points about the education innovations introduced in the subject, as are the concept maps. In the second part, the student must assess a total number of 13 items, in a scale of 0 to 10 points, including the concept maps.

\section{Results and discussion}

\subsection{Evaluation tool}

Related the application of concept maps as an evaluating tool the first day of class, it has to be commented that the students had a very positive attitude to this activity. In fact, they did not expect an active methodology the first day of class since normally lecturers just present the subject index. In general, the activity development showed the lack of required previous knowledge. As a consequence, it was necessary to help students by contributing with support material (blind diagrams and the key words). The activity carried out in groups let students to complement each other concerning the previous knowledge. At the end of the 
activity, students recognized the activity not only as an evaluation tool for the lecturer, but also as a self-assessment tool.

It has to be highlighted that the feedback obtained during the activity allowed the lecturer to establish a start point for the subject contents. Finally, it was observed that the presentations of the concept maps to the whole class group and the discussions the different proposals improved the communicative skills of the students. These results can be stated if it is compared with the same students in previous subjects and courses (for example in Waste Water Engineering) in which the concept map as evaluating tool is not yet applied.

\subsection{Knowledge organizing tool}

Concerning the results obtained using concept maps as a knowledge organizing tool, specifically for the application "Overview of the subject contents the first day class", it was observed that students pay more attention and they detect their weak points regarding the required previous knowledge. In this way, students are called for refreshing concepts to follow and understand the subject properly.

For the other case, the application "Remembering introduction", it was detected that students follow-up the classes easier, in fact they attended most of them and students who abandoned this subject were negligible. Besides, students use the concept maps of the lecturer as a model and enlarger them. As students recognize, this application tool improves the following, understanding, and learning of the subject.

These subjective results can be confirmed since the lecturer gives classes in the same subject before and after applying concept maps as knowledge organizing tool.

\subsection{Meaningful learning tool}

a) Concept maps achieved in teamwork and used as meaningful learning tool

Regarding to the opinion poll about concept maps achieved in the subject "Chemical Processes Technology", in which they were used as meaningful learning tool, results are shown in Figure 4. This opinion poll was previous to the exam. 


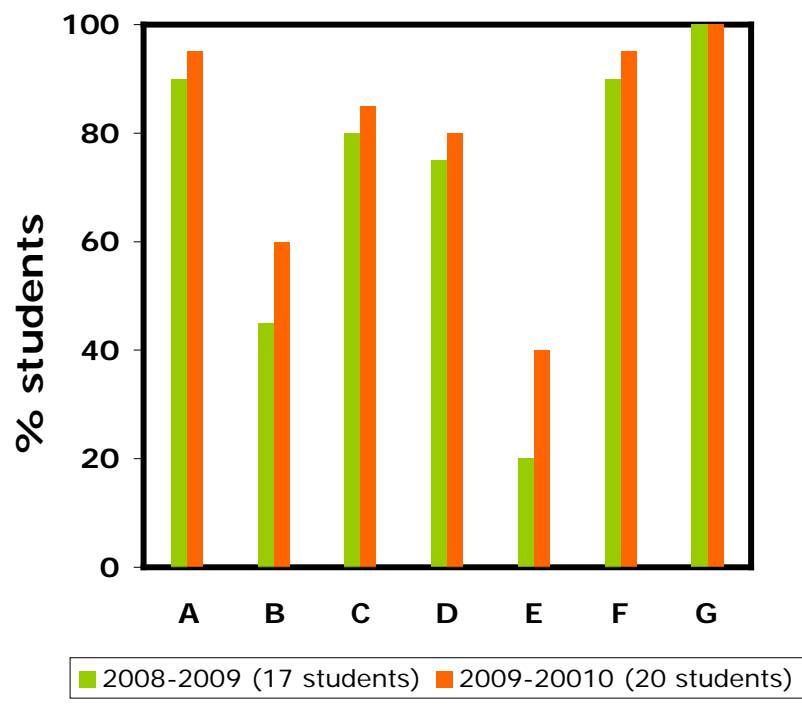

The concept maps are useful to:

A. Selection of key ideas

B. Meaningful learning

C. Review the lesson for the exam

D. Make the learning easy

E. Mistakes diagnosis

F. Comprehensive view of the lesson

G. Bring up the subject

Figure 4. "Results of the opinion poll about the usefulness of the concept maps in the subject Chemical Processes Technology".

Results shown in Figure 4 indicate that students used the concept maps fundamentally to select the most important concepts of the lesson (A) and to obtain an overview of it (F), allowing both facts to bring up the subject (G).

Table 1 shows the final marks obtained by the students in the academic years in which they use concept maps (2008-2009 and 2009-2010) and in the last course in which they do not use concept maps (2005-2006).

\begin{tabular}{|c|c|c|c|}
\cline { 2 - 4 } \multicolumn{1}{c|}{} & \multicolumn{3}{c|}{$\%$ students } \\
\hline \multirow{2}{*}{ Marks } & $\begin{array}{c}\text { Without } \\
\text { concept maps }\end{array}$ & \multicolumn{2}{c|}{ With concept maps } \\
\cline { 2 - 4 } & $\begin{array}{c}\mathbf{2 0 0 5 - 2 0 0 6} \\
(15 \text { students) }\end{array}$ & $\begin{array}{c}\mathbf{2 0 0 8 - 2 0 0 9} \\
(17 \text { students })\end{array}$ & $\begin{array}{c}\text { 2009-2010 } \\
\text { (20 students) }\end{array}$ \\
\hline 10 & 5 & 15 & 14 \\
\hline $9-9.9$ & 15 & 23 & 22 \\
\hline $7-8.9$ & 40 & 31 & 32 \\
\hline $5-6.9$ & 10 & 8 & 9 \\
\hline $0-4.9$ & 10 & 8 & 9 \\
\hline No mark & 20 & 15 & 14 \\
\hline
\end{tabular}

Table 1. "Final marks of the subject Chemical Processes Technology".

These results show that the percentage of students with marks in the range $0-4.9$, 5-6.9 and 7-8.9 diminished while those in the range 9-9.99 and 10 notably increased when the concept maps were used by the students. In fact, the 
percentage of students with 10 increased three times. It is also outstanding the fact that the percentage of students that did not take the exam diminished the academic years in which concept maps were used as learning tool.

It is important to take into account that the contribution of the concept maps to the final mark of the subject was only the $5 \%$ (the mark obtained in the exam contributed the $80 \%$ and that obtained in the teamwork the $15 \%)$. Therefore, the percentage that corresponds to the construction of the concept maps is not enough important to increase perceptibly the final mark. The increase in the final marks was then attributed to the fact that the concept maps promote the meaningful learning, leading to obtain better marks in the final exam.

b) Concept maps achieved individually and used as meaningful learning tool

Table 2 shows a comparison of the final marks obtained by the students in the subject of "Analytical Techniques of the Environment" between the academic years in which they do not use concept maps (from 2000-2001 to 2006-207) and the academic years in which they use concept maps (from 2007-2008 to 2009-2010).

\begin{tabular}{|c|c|c|c|c|c|c|c|c|c|c|}
\hline \multirow[b]{3}{*}{ Marks } & \multicolumn{10}{|c|}{$\%$ students } \\
\hline & \multicolumn{7}{|c|}{ Without concept maps } & \multicolumn{3}{|c|}{ With concept maps } \\
\hline & 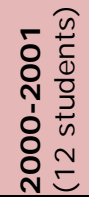 & 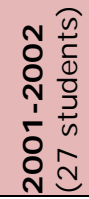 & 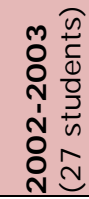 & 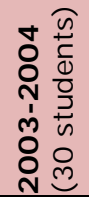 & 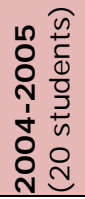 & 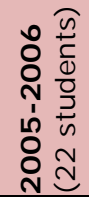 & 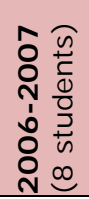 & 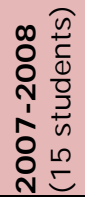 & 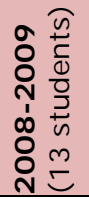 & 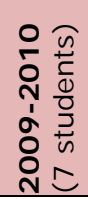 \\
\hline 10 & 0 & 0 & 0 & 0 & 0 & 5 & 0 & 7 & 0 & 0 \\
\hline $9-9.9$ & 8 & 18 & 11 & 7 & 0 & 9 & 37 & 13 & 15 & 100 \\
\hline $7-8.9$ & 34 & 37 & 44 & 40 & 75 & 86 & 63 & 60 & 85 & 0 \\
\hline $5-6.9$ & 25 & 15 & 30 & 20 & 20 & 0 & 0 & 0 & 0 & 0 \\
\hline $0-4.9$ & 8 & 4 & 0 & 0 & 0 & 0 & 0 & 0 & 0 & 0 \\
\hline No mark & 25 & 26 & 15 & 33 & 5 & 0 & 0 & 20 & 0 & 0 \\
\hline
\end{tabular}

Table 2. "Final marks of the subject Analytical Techniques of the Environment".

These results show that the percentage of students with marks in the range 7-8.9, 9-9.99, and 10 increased when the concept maps were used by the students. In fact, in the academic year 2009-2010 all the students obtained a mark in the range 9-9.9. 
Table 3 shows the results of first part of the opinion poll about the strong points and the weak points in the concept maps in the subject of "Analytical Techniques of the Environment", in which they were used as meaningful learning tool. These results correspond to the academic years since 2007-2008 to 2009-2010. Table 3 indicate the total number of opinion poll processed each academic year and the percentage of the registered students that it represents.

In the identification of the strong points in the field of the concept maps, the polled students indicated that the concept maps helped to:

- Understand the concepts in each lesson.

- Follow the subject continuosly.

- Extract the main ideas of each lesson.

- Provide a global viewpoint of each lesson.

- Learn.

- Review each lesson.

- Synthesize each lesson.

- Remember the concepts.

In the identification of the weak points in the field of the concept maps, the polled students indicated that:

- The format might not be limited to A4.

- They resulted more laborious (high workload).

- In some lessons there were a lot of concepts and it was difficult to relate this concepts. 


\begin{tabular}{|c|c|}
\hline \multicolumn{2}{|c|}{ 2007-2008: 7 polled students ( $47 \%$ of the registered students) } \\
\hline Strong points & $\%$ students \\
\hline $\begin{array}{l}\text { They help to understand the concepts in each } \\
\text { lesson. }\end{array}$ & 57 \\
\hline They allow to follow the subject continuosly. & 43 \\
\hline They help to extract the main ideas of each lesson. & 14 \\
\hline They provide a global viewpoint of each lesson. & 14 \\
\hline They demand a effort of synthesis. & 14 \\
\hline They help to learn. & 14 \\
\hline Weak points & $\%$ students \\
\hline The format might not be limited to A4. & 43 \\
\hline They result more laborious. & 29 \\
\hline \multicolumn{2}{|c|}{ 2008-2009: 3 polled students ( $23 \%$ of the registered students) } \\
\hline Strong points & $\%$ students \\
\hline They are useful to review each lesson. & 67 \\
\hline They are useful to synthesize each lesson. & 33 \\
\hline They help to extract the main ideas of each lesson. & 33 \\
\hline Weak points & $\%$ students \\
\hline They demand high workload. & 67 \\
\hline \multicolumn{2}{|c|}{ 2009-2010: 5 polled students ( $71 \%$ of the registered students) } \\
\hline Strong points & $\%$ students \\
\hline $\begin{array}{l}\text { They help to understand the concepts in each } \\
\text { lesson. }\end{array}$ & 60 \\
\hline They help to remember the concepts. & 40 \\
\hline $\begin{array}{c}\text { Weak points } \\
\end{array}$ & $\%$ students \\
\hline They demand high workload. & 60 \\
\hline $\begin{array}{l}\text { In some lessons there are a lot of concepts and it } \\
\text { is difficult to relate this concepts. }\end{array}$ & 20 \\
\hline
\end{tabular}

Table 3. "Results of the opinion poll about the strong points and weak points in the concept maps in the subject Analytical Techniques of the Environment".

On the other hand, Table 4 shows the results of the second part of the opinion poll, which correspond to the item about the usefulness of the concept maps. Table 4 shows the mark and the standard deviation in the academic years since 2007-2008 to 2009-2010. The item about the usefulness of the concept maps obtained a mark in the range of 7.00-8.57, with a standard deviation in the range of 1.00-1.82.

\begin{tabular}{|c|c|c|}
\hline Academic year & Mark & Standard deviation \\
\hline $2007-2008$ & 8.57 & 1.82 \\
\hline $2008-2009$ & 7.50 & 1.34 \\
\hline $2009-2010$ & 7.00 & 1.00 \\
\hline
\end{tabular}

Table 4. "Results of the opinion poll about the usefulness of the concept maps in the subject Analytical Techniques of the Environment". 


\subsection{Competences developed}

The realization of concept maps allow the student to obtain new learn strategies and to develop generic competences. These generic competences are shown in Table 5.

The generic competences identify elements that can be common to some degree, according with the "Tuning Educational Structures in Europe, 2003" project (Instituto de Ciencias de la Educación de la UPV, 2006). The generic competences to develop are:

- Information management skills.

- Capacity for analysis and synthesis.

- Basic general knowledge in the field of study.

- Teamwork.

- Ability to work in an interdisciplinary team.

- Capacity to learn.

- Ability to work autonomously.

\begin{tabular}{|l|l|}
\hline \multicolumn{1}{|c|}{ Generic competences } & \multicolumn{1}{c|}{ Types of competences } \\
\hline $\begin{array}{l}\text { Instrumental competences: cognitive abilities, } \\
\text { methodological abilities, technological abilities and } \\
\text { linguistic abilities. }\end{array}$ & $\begin{array}{l}\text { Information management skills. } \\
\text { Capacity for analysis and synthesis. } \\
\text { Basic general knowledge in the field of study. }\end{array}$ \\
\hline $\begin{array}{l}\text { Interpersonal competences: individual abilities } \\
\text { like social skills (social interaction and co- } \\
\text { operation). }\end{array}$ & $\begin{array}{l}\text { Teamwork. } \\
\text { Ability to work in an interdisciplinary team. }\end{array}$ \\
\hline $\begin{array}{l}\text { Systemic competences: abilities and skills } \\
\text { concerning whole systems (combination of } \\
\text { understanding, sensibility and knowledge; prior } \\
\text { acquisition of instrumental and interpersonal } \\
\text { competences required). }\end{array}$ & $\begin{array}{l}\text { Capacity to learn. } \\
\text { Ability to work autonomously. }\end{array}$ \\
\hline
\end{tabular}

Table 5. "Generic competences to develop by the students through the aplication of the concept maps".

The consecution of these skills has been verified by means the opinion polls about the usefulness of the concept maps (Figure 4 and Table 3 ), in which items related to these generic competences have been considered. 


\section{Conclusions}

- Students consider the concept maps useful principally to select key ideas, to achieve a comprehensive view of the lesson, and to bring up the subject.

- Concept maps promote the meaningful and active learning, leading to obtain better marks in the final exam.

- Concept maps allow organize the learning with the goal of learning, not of memorizing.

- Concept maps allow to follow the subject continuously.

- Concept maps demand an effort of synthesis.

- Concept maps can be used as an evaluating tool, testing the previous knowledge related to a subject which understanding is basic to continue learning or also during the teaching-learning process.

- Concept maps as a knowledge organizing tool help students to understand, follow-up, and learn subjects with a high load of contents.

- The development of these activities in teams let students to get better their social capabilities.

- The presentation and discussion of concept maps improve communicative skills of the students.

- The realization of concept maps allows that the student to develop generic competences.

\section{Future research}

One line of future research consists in the development of the backward activity, that is, the lecturer will supply the concept map of a lesson, and the student (alone or in groups) will develop the lesson from the concept map. 


\section{Acknowledgements}

Authors thank ICE of Universidad Politécnica de Valencia for contributing in our teaching training by means their specific formation and motivate us in continuing in this education task.

\section{References}

Alonso, J. (2001). Motivación y estrategias de aprendizaje. Principios para su mejora en alumnos universitarios. Madrid: Didáctica universitaria. Ed: La Muralla.

Alonso, J., \& Araya, C. (2008). Concept Mapping as an Assessment Tool in Higher Education Activities. Paper presented in the Third International Conference on Concept Mapping, Finland.

Ausubel, D.P. (1968). Educational Psychology: A Cognitive View. New York: Holt, Rinehart \& Winston.

Ausubel, D. P. (2002). Adquisición y Retención del Conocimiento. Una Perspectiva Cognitiva. Barcelona: Ed. Paidós.

Chen-Chung, L., Holly, C., Ju-Ling, S., Guo-Ting, H., \& Baw-J hiune, L. (2011). An Enhanced Concept Map Approach to Improving Children's Storytelling Ability. Computers \& Education, 56 (3), 873-884.

González, F., Ibáñez, F., Casalí, J., López, J., \& Novak, J.D. (2000). Una aportación a la mejora de la calidad de la docencia: Los mapas conceptuales. Pamplona: Servicio de Publicaciones de la Universidad Pública de Navarra. ISBN: 84-9507538-5.

Haugwitz, M., Nesbit, J. \& Sandmann, A. (2010). Cognitive Ability and the Instructional Efficacy of Collaborative Concept Mapping. Learning and Individual Differences, 20 (5), 536-543. doi: 10.1016/j.lindif.2010.04.004

Hay, D., Kinchin, I., \& Lygo-Baker, S. (2008). Making learning visible: the role of concept mapping in higher education. Studies in Higher Education, 33 (3), 295311.

doi: $10.1080 / 03075070802049251$ 
Heinzefry, J.A., \& Novak, J. D. (1990). Concept mapping brings long-term movement toward meaningful learning. Science Education, 74 (4), 461-472.

HIMC Cmap Tools from http://cmap.ihmc.us/download

Ifenthaler, D. (2010). Bridging the Gap between Expert-Novice Differences: The Model-Based Feedback Approach. Journal of Research on Technology in Education, 43 (2), 103-117.

Instituto de Ciencias de la Educación de la UPV (2006). Plan de Acciones para la Convergencia Europea (PACE). Guía Docente de la UPV: Criterios para su elaboración. Valencia: Servicio de Publicaciones de la Universidad Politécnica de Valencia. V-2201-2006.

Novak, J.D. (1982). Teoría y Práctica de la Educación. Madrid: Ed. Alianza.

Novak, J.D. (1998). Conocimiento y Aprendizaje: Los Mapas Conceptuales como Herramientas Facilitadoras para Escuelas y Empresas. Madrid: Alianza, D.L.

Novak, J. D., \& Gowin, D.B. (1988). Aprendiendo a Aprender. Barcelona: Martínez Roca.

Ontoria Peña, A. (2004). Mapas Conceptuales: Una Técnica para Aprender. Madrid: Narcea, D.L.

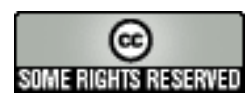

Article's contents are provided on a Attribution-Non Commercial 3.0 Creative commons license. Readers are allowed to copy, distribute and communicate article's contents, provided the author's and Journal of Industrial Engineering and Management's names are included. It must not be used for commercial purposes. To see the complete license contents, please visit http://creativecommons.org/licenses/by-nc/3.0/. 